\title{
Computerised visual field deficits in tears of the retinal pigment epithelium
}

Joseph I Maguire, William H Annesley Jr, William L Decker, Gary C Brown, David H Fischer, Joan M Slagle

\begin{abstract}
Retinal Pigment epithelial tears have been well documented as a complication of pigment epithelial detachment in patients with age related macular degeneration. Spontaneous and iatrogenic separation of detached retinal pigment epithelium, with subsequent retraction and exposure of the underlying choriocapillaris and Bruch's membrane, usually results in poor visual function in the affected areas. However, exact characterisation of the resultant scotomas has not been previously described. We present two patients with spontaneous pigment epithelial tears who underwent Octopus computerised visual field analysis. The density and characteristics of their associated field loss is compared with their clinical and fluorescein angiographic appearance.
\end{abstract}

Retinal pigment epithelial tears or rips were first described by Hoskin et $a l^{1}$ in 1981 as a newly recognised complication of age related macular degeneration in patients with associated pigment epithelial detachments. Several authors have since reported on this phenomenon..$^{2-7}$ Associated visual loss is usually abrupt and severe when the foveal or parafoveal area is involved. ${ }^{1-6}$ Casswell and associates ${ }^{5}$ noted a $10 \%$ incidence of spontaneous tears during routine follow-up examinations in at risk patients. These typically occurred in eyes with late fluorescent pigment epithelial detachments, and usually within a few months of presentation.

To our knowledge the characterisation of scotomata associated with RPE tears has not been considered. For this reason the reproducible quantification of associated scotomata by computerised visual fields was performed to evaluate the visual field loss and compare it with the clinical and fluorescein angiographic appearance.

Retina Service, Wills Eye Hospital, Thomas Jefferson University, Philadelphia, USA J I Maguire W H Annesley Jr W L Decker G C Brown D H Fischer J M Slagle

Correspondence to: Joseph I Maguire, MD, Retina Service, Wills Eye Hospital, Ninth and Walnut Streets, Philadelphia, PA 19107, USA

Accepted for publication 22 February 1990

\section{Patients and methods}

Two patients aged 60 and 70, were examined on the Wills Eye Retina Service for age related macular degeneration with associated pigment epithelial detachment. Both were noted to epithelium. Neither patient had clinical evidence or a past history compatible with glaucoma, optic neuropathy, or retinal vascular disease.

Computerised visual fields were calculated by the Octopus 201 static perimeter. Basic software programs 31 and 32 were used to define grossly the visual field abnormalities. Higher resolution, with detailed definition of the defects, was develop spontaneous tears of the retinal pigment obtained with advanced software. Octopus multiple-use user defined programs (UDP) CO-4 and $\mathrm{CO}-8$ were employed. Both patients gave reliable responses to the tests.

Initial testing was carried out with standard $30^{\circ}$ radius visual fields with $6^{\circ}$ of resolution (programs 31 and 32). These programs were useful in attempting to roughly define the location, size, shape, and contour of the scotomas. Multiple-use UDP programs CO-4 and $\mathrm{CO}-8$ were then used to define closely the visual field loss. Resolution of $1^{\circ}$ and $2^{\circ}$, respectively, allowed detailed characterisation of the scotoma. $\mathrm{CO}-8$ is an $8^{\circ}$ radius visual field, $\mathrm{CO}-4$ is a $4^{\circ}$ radius visual field; both test 57 points, double determining nine of these points.

\section{Case reports}

CASE I

A 70-year-old male was first seen in September 1981 complaining of decreased vision and metamorphopsia in his left eye. His visual acuity was $20 / 25$ in the right eye and $20 / 400$ in the left eye. Funduscopic examination revealed changes consistent with bilateral age related macular degeneration (ARMD) and a subretinal neovascular membrane in the left macula.

Subsequent follow-up was uneventful unti March of 1986, when a detachment of the retinal pigment epithelium was observed inferotemporal to the fovea in the right eye; visual acuity was 20 / 30. Six weeks later the patient noted a sudden decrease in vision to 20/80. A pigment epithelial tear, along the temporal edge of the previously recorded pigment epithelilal detachment (PED), was noted. Nasal retraction of the pigment epithelium exposed underlying choroid up to the edge of fixation.

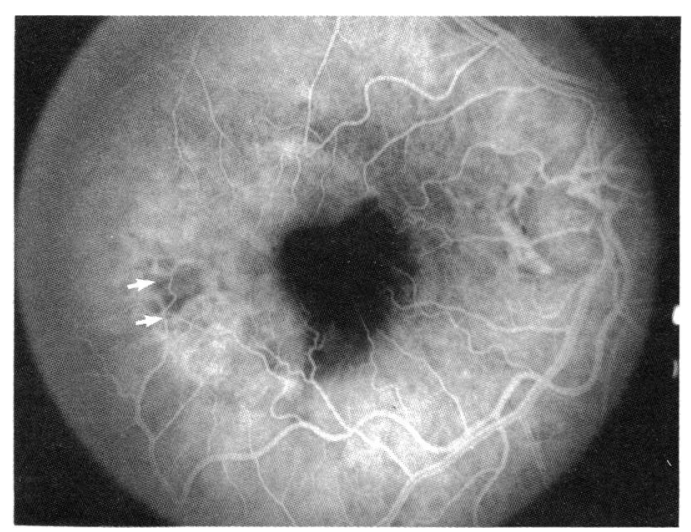

Figure 1: Case 1. A fluorescein angiogram at 36 seconds after injection shows early hyperfluorescence in the area of absent retinal pigment epithelium (arrows). 


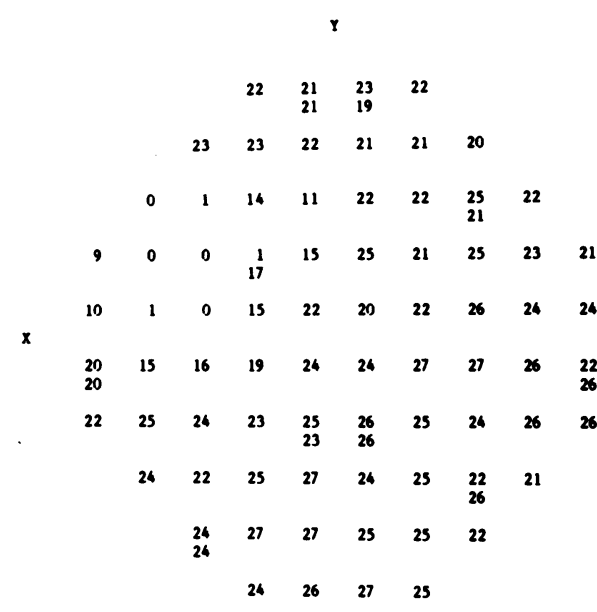

Figure 2: Case 1. Octopus program 32 grossly outlines a large area of marked decibel loss just superonasal to fixation in the right eye.

Fluorescein angiography showed a C-shaped area of mottled hyperfluorescence increasing in the late frames and corresponding to the exposed choroidal vasculature. The retracted pigment epithelium resulted in block choroidal fluroescence (Fig 1).

Octopus computerised static perimetry was performed three weeks after diagnosis of the pigment epithelial tear. A standard $30^{\circ}$ radius central visual field (program 32) was initially used to outline grossly the extent of the scotoma located superotemporal to fixation (Fig 2). Closer definition of the nasal aspect of the tear, with its retracted pigment epithelium, was accomplished with the UDP CO-8 (Fig 3). Both fields revealed an absolute or near absolute scotoma in areas with absent pigment epithelium. However, decibel loss in the area containing retracted pigment epithelium was minor.

\section{CASE 2}

A 60 year-old woman with a history of ARMD was seen in May 1982 with a history for several months of decreased visual acuity and distortion of her vision in the right eye. Visual acuity was $20 / 40$ in the right eye and 20/30 in the left eye.

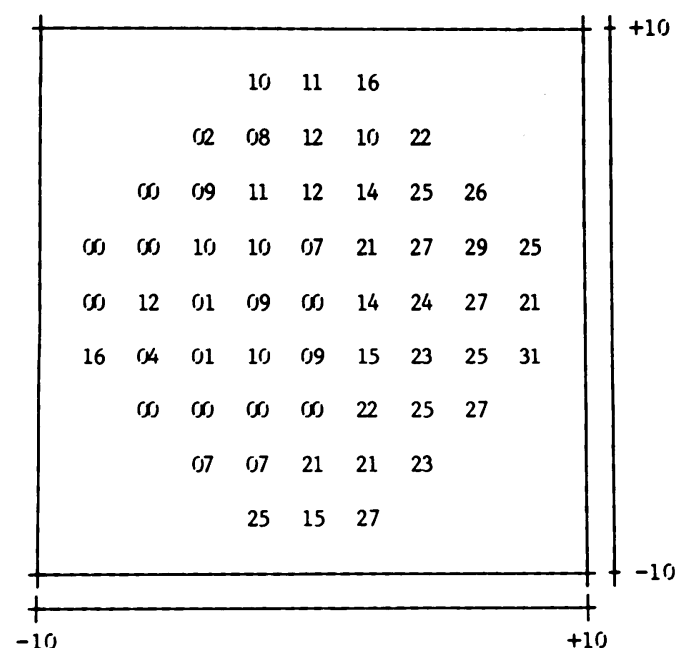

Figure 3: Case 1. Closer evaluation of the right eye with the CO-8 program details a dense central scotoma with a border of moderate decibel loss.

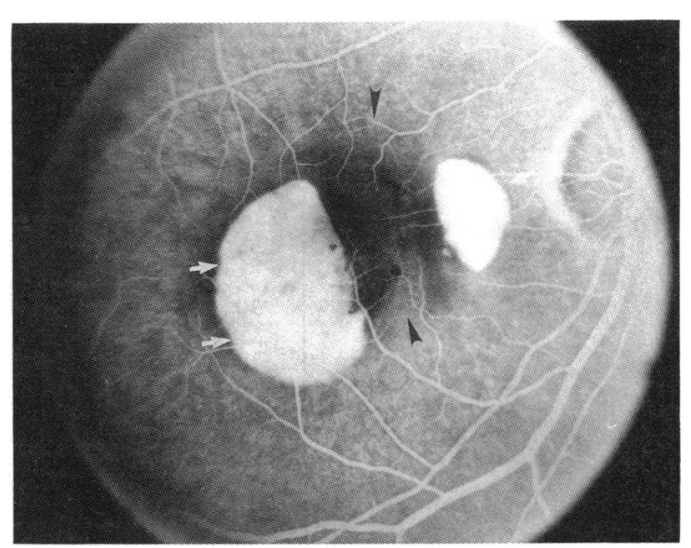

Figure 4: Case 2. Fluorescein angiography of the right eye at 35 seconds after injection discloses hyperfluorescence in the area of absent retinal pigment epithelium (arrows). The pigment epithelium has retracted centrally towards the fovea black (arrowheads).

Funduscopic examination revealed a PED of the left eye with scattered drusen. The right eye had numerous drusen and a double pigment epithelial tear. One tear was nasal and the other temporal to fixation. Fluorescein angiography showed retraction of the retinal pigment epithelium centrally on both sides of the fovea. Areas where retinal pigment epithelial was absent showed marked hyperfluorescence (Fig 4).

Octopus computerised static perimetry was performed one year later with a standard $30^{\circ}$ radius field, which failed to delineate visual field loss (Fig 5). Higher resolution UDP programs CO-4 and CO-8, however, defined precisely the position of absolute decibel loss corresponding to the clinical position of the two pigment epithelial tears. Normal visual function was maintained centrally between the tears where retracted pigment epithelium was present (Fig 5, 6, 7). Sixty months after initial presentation the patient's clinical appearance and visual acuity remain unchanged.

\section{Discussion}

Tears of the retinal pigment epithelium are a known complication of pigment epithelial

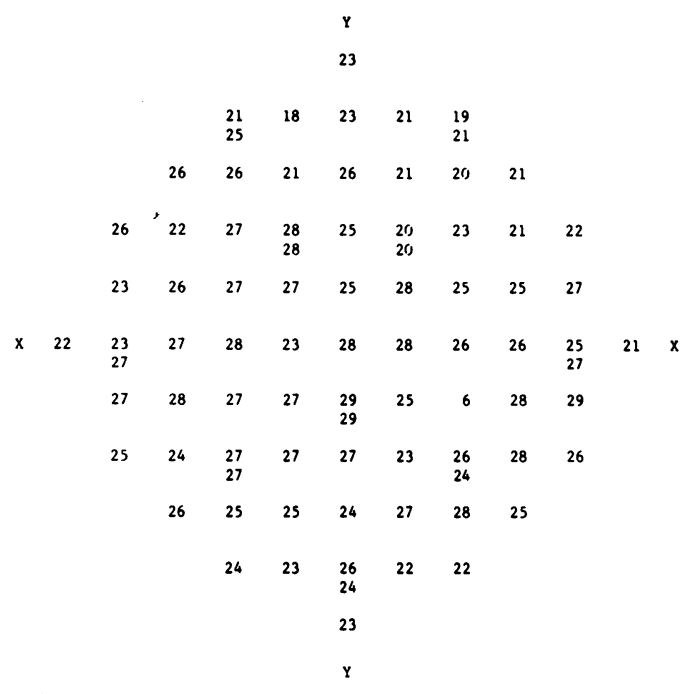

Figure 5: Case 2 Standard $30^{\circ}$ radius visual field fails to show defects. 


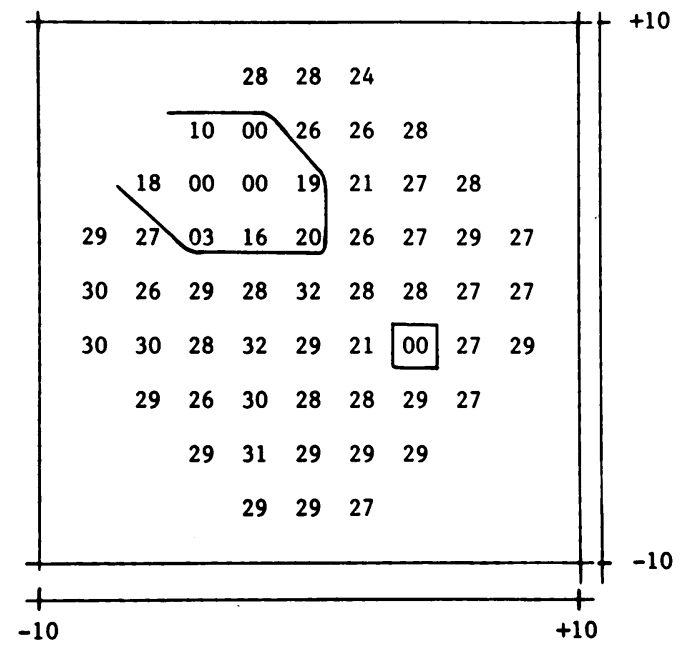

Figure 6

Figures 6 and 7: Case 2. CO-8 and CO-4 visual fields, respectively, are able to resolve two areas of absolute scotomata. These field defects correspond to the areas of absent retinal pigment epithelium. Fixation is preserved, which explains continued normal visual acuity.

detachments associated with ARMD. They result in retraction of the pigment epithelial layer towards the PED centre and away from the line of cleavage. The overlying sensory retina remains intact but unsupported by the retinal pigment epithelial monolayer. Angiographically, retracted retinal pigment epithelium blocks choroidal fluorescence, whereas adjacent areas devoid of retinal pigment epithelium are hyperfluorescent.

Although tears occurring in the central macular area have a poor visual prognosis, the nature and density of the resultant scotomas have not been well described. Computerised static perimetry, with resolution up to $1^{\circ}$ of visual field, allows characterisation of the resultant scotomas when compared with the clinical appearance. In our two patients an absolute scotoma developed where retinal pigment epithelium no longer supported sensory retina. Conversely, adjacent areas containing retracted retinal pigment epithelium continued to function at normal or near normal levels, with minimal or no decibel loss. Although the patient described in our first case had visual field testing within one month after his retinal pigment epithelial tear, our second patient was not tested until one year afterwards. Both had absolute visual field defects implying the permanence of these changes.

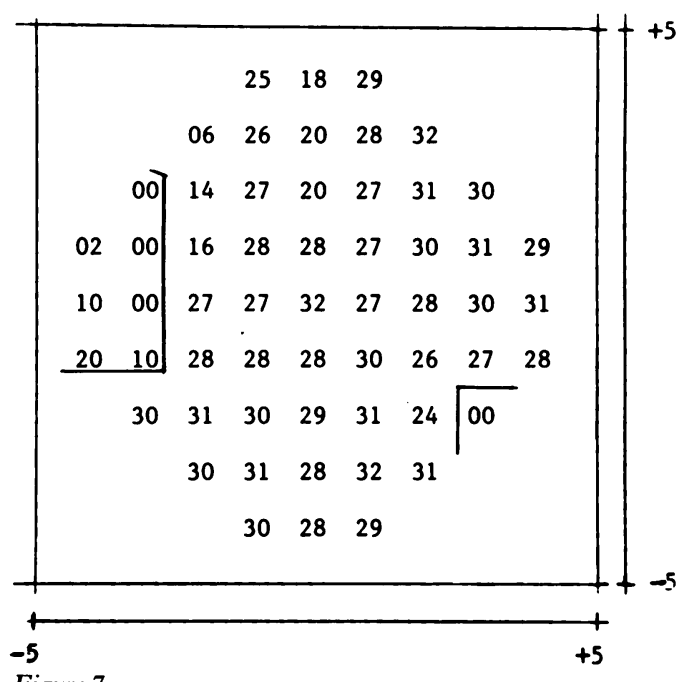

The onset of visual dysfunction probably depends on loss of the physical, and therefore metabolic link between photoreceptors and pigment epithelium. Hoskin and colleagues' report noted one patient whose visual acuity decreased from $20 / 30$ to $20 / 200$ over several days after a tear developed. ${ }^{\prime}$ This drop in vision coincided with the onset of structural changes described in animal models of sensory retinal detachments. ${ }^{8}$ Of the 44 eyes with pigment epithelial tears reported by Hoskin and associates only eight retained a normal anatomical relationship between foveal retinal pigment epithelium and photoreceptors.' All, as in case 2, retained good visual acuity.

This work was supported in part by the Retina Research and Development Foundation, Philadephia.

1 Hoskin A, Bird AC, Sehmi K. Tears of detached retina pigment epithelium. Brf Ophthalmol 1981; 65: 417-22.

pigment epithelium. Brf Ophthalmol 1981; 65: 417-22.
Gass JDM. Pathogenesis of tears of the retinal pigment Gass JDM. Pathogenesis of tears of the re
epithelium. Brf Ophthalmol 1984; 68: 513-9.

3 Moorfields Macula Study Group. Retinal pigment epithelial detachments in the elderly: a controlled trial of argon laser photocoagulation. BrF Ophthalmol 1982; 66: 1-16.

4 Elman MJ, Fine SL, Murphy RP, et al. The natural history of serous retinal pigment epithelium detachment in patients with age-related macular degeneration. Ophthalmology 1986 93: $224-30$.

5 Casswell AG, Kohen D, Bird AC. Retinal pigment epithelia detachments in the elderly: classification and outcome. $\mathrm{Br} \mathcal{F}$ Ophthalmol 1985; 69: 397-403.

6 Decker WL. Sanborn GE, Ridley M, et al. Retinal pigmen epithelial tears. Ophthalmology 1983; 90: 507-12.

7 Chaung EL, Bird AC. The pathogenesis of tears of the retina pigment epithelium. Am f Ophthalmol 1988; 105: 285-90.

8 Kroll AJ, Machemer R. Experimental detachment in the owl monkey. III. Electron microscopy of the retina and pigment epithelium. Am $\mathcal{F}$ Ophthalmol 1968; 85: 410-27. 